\title{
Healthy Cities of Tomorrow: the Case for Large Scale Built Environment-Health Studies
}

\author{
Chinmoy Sarkar • Chris Webster
}

Published online: 23 January 2017

(C) The New York Academy of Medicine 2017

\section{Introduction}

In urban economics and planning theory, the net benefits of living in cities rise to a threshold and then falls. The rise happens as more and more people clustering together in space generate more and more agglomeration benefits such as more and better services, greater choice of shops and jobs, better choice of employees in terms of profound and diverse skill sets, lower waiting times between jobs and better flow of specialist knowledge between firms [1]. The falling portion of the curve kicks in as the costs of crowding outweigh the benefits. The inverted U-shaped curve not only describes the cost-benefits of agglomeration generally but is also a plausible description of specific classes of benefits. Health is one of these that has recently gained prominence in public and scientific discussion. Do urban health costs follow an inverted U-shaped curve? A hypothesized relationship between density, net benefits and cost and effects on population health is illustrated in Fig. 1.

Public health is purchasable. Within natural limitations a community can determine its own death rate.

Herman N. Biggs, 1913

Commissioner of Health for New York State.

C. Sarkar $(\bowtie) \cdot$ C. Webster

Healthy High Density Cities Lab, HKUrbanLab, The University of Hong Kong, Knowles Building, Pokfulam Road, Pok Fu Lam, Hong Kong

e-mail: csarkar@hku.hk

C. Webster

Department of Land Economy, Cambridge University, 19 Silver Street, Cambridge CB3 9EP, UK
To answer the question, consider two extremes: a country comprising remote countryside with isolated smallholdings and a country comprising cities built at the maximum density given technological, economic and social constraints (maximum dispersal versus maximum clustering). For the thought experiment, imagine that the two distinct populations are equal and equally wealthy in terms of composition, size, SES and baseline health status.

The dispersed population would face health benefits from exposures to fresh air, green and blue spaces and perhaps access to locally sourced fresh food (though smallholding is an arduous activity). They would face health costs of long response times for emergency vehicles, lack of access to specialist medical expertise and generally a poorer service due to lack of competition among suppliers (since health service centres would be spread out, each with its own spatial monopoly). On emergency response time cost alone, many more people would die in this country than in the heavily urbanized country. Lower densities may also be associated with reduced levels of social support and interactions, while a lower employment density will mean more vehiclemiles travelled and longer commute times.

On the other hand, the concentrated population of highly urbanized country has the advantage of service concentration, specialization and rapid response to critical health events such as heart attack, stroke, respiratory failure and accidents, but relatively higher risks of infectious and chronic diseases related to city life. One explanation for Hong Kong's internationally leading life expectancy statistics is its high density: individuals suffering a critical health 


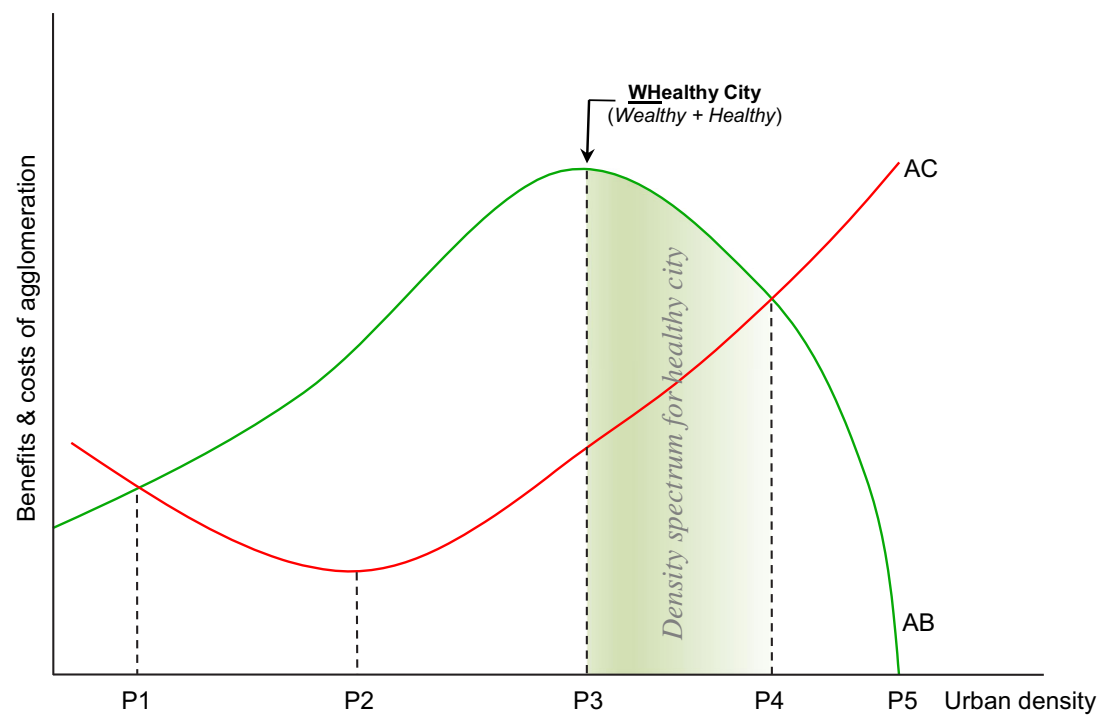

Fig. 1 Relationship between urban density, net benefits and costs and population health (adapted from the Webster \& Lai, 2003; Sarkar, Webster \& Gallacher, 2014). Notes: $A B$ average net benefits, $A C$ average costs. P1: Minimum density (low benefits and cost, low service and employment density, high transaction cost, poor public transport, car-dependant, low social support, higher exposure to green and blue space, reduced congestion and pollution). P2: Urban density sustaining lowest cost (higher benefits than P1 and with lowest costs). P3: Optimal urban density (highest density sustaining maximum benefits, high employment density and mix, minimum transaction cost, optimized services, optimized design, highly evolved public spaces, fully developed public

event are quickly discovered and quickly taken to hospital where there is a high density of professionals with specialist emergency skills. High density will also mean higher land use heterogeneity, higher concentration of retail and other service destinations and the resulting higher employment- and job-mix: all attributes known to reduce commute times, promote active lifestyle and enhance a sense of community operationalized through access to walkable services, attractive destinations and activity spaces promoting social interactions. But the high concentration of people in sedentary occupations in a highly urbanized society creates additional health risks, including respiratory disease, mental health problems, obesity, cardiovascular disease and traffic and other accidents. The probability of propagation of infectious disease via highly dense urban networks increases exponentially and so are the associated risks. In dystopian cities with densities of six people per room as is currently encountered in some of the overcrowded informal settlements of rapidly urbanizing cities of developing countries, China for example [2], such health risks become acute. transport, active travel behaviour, highest sense of community and social capital). Towards P4: Higher density towards socially optimal city (higher density than P3 on account of skilled migrant work force, higher heterogeneity in social class, higher distributed net benefits, highest employment density and mix, very good services, good design, well developed public transport, active travel behaviour, sense of community and social capital). P5: Urban malaise (overcrowding, congestion, pollution, resources, services and infrastructure constrained beyond carrying capacities, higher deprivation and inequality, higher stress of urban stress, informal economy)

In wealthy countries and cities, the negative effects of crowding on health risk may be strongly mitigated by positive gains in health care access. The net health benefit curve is income and social-status dependent, the more so, the more inequitable the health care systems. The shape of the theoretically U-shaped net crowding cost curve is empirically determined. The easier it is to mitigate congestion costs (air, traffic, water, health risks), the greater the probability of net benefits continuing to grow as density increases. This rarely pertains across income groups; however, since in advanced as well as poor cities, households on the lowest income seem willing to assume very significant individual and even more significant public health risks for the sake of earning urban wages.

Between the two extremes of maximally disbursed and maximally concentrated populations lie most of the world's urban systems. An economy's system of cities tends to evolve naturally in a way that people move from one location to another in search of higher welfare, including higher income, educational opportunities and 
health. Only if an entire urban system is completely dystopian will people remain living in an urban malaise characterized by exposures to multiple forms of deprivation, environmental hazards and increasing socioeconomic disparity. Nineteenth century Londoners eventually dispersed to the suburbs, new towns, country towns, secondary and tertiary cities and to the regions. So we propose as a general proposition that urban health plotted against city size or density broadly follows a Ushape curve. Health indicators should go up as the population clusters but too much clustering leads to higher risks of both infectious and sedentary diseases respectively; the predominant urban health challenges faced by the nineteenth and twenty-first century Western cities.

Such broad propositions generally constitute the first step in developing a science of healthy city planning. A second step tests such propositions empirically, for example, measuring the relationship between urban density or settlement size and specific health outcomes. A third series of steps (still in its developmental stages) would be to make the propositions more sophisticated, for example, moving beyond a focus on density alone, to examine the causal relationship over time of other urban multi-scalar micro-dynamics including specific morphological, design, environmental quality and organizational attributes with behavioural and health outcomes. The importance of the latter, especially their role in guiding scientifically informed policy interventions is becoming acknowledged in a growing body of literature on the science of healthy cities (summarized in 'In pursuit of better evidence' section).

New scientific evidence generated over the past decade points to a significant role played by a myriad of attributes of our cities' built environments (BE) in shaping human behaviour, health and well-being [3-6]. This has resulted in a renaissance of interest in an environmental model of public health, comprising interventions specific to physical and social environments [7, 8]. We view this as similar to the wave of public health interest that gave birth to modern town planning in the mid to late twentieth century. Non-clinical environmental interventions in the form of health-specific planning and design of neighbourhoods and cities have been scientifically shown to have significant potential in playing a role in creating healthy cities of tomorrow. In addition to enabling healthier lifestyles, such interventions can produce higher cost effectiveness ratios in health service provision and can thus play a part in reducing future health expenditures [9]. The creation of healthy cities will entail a much closer integration and synergy between the disciplines of public health, epidemiology, transport planning, urban planning and design.

In the recent years several ongoing projects have emerged that aim specifically to measure health-specific components of urban environments at a large scale. The ultimate objective is to eventually link them with existing health cohorts enabling interdisciplinary collaborations and evidence generation towards creation of healthy cities. The Place, Health and Liveability project is one such national-level study aiming to create neighbourhood-level spatial measures of urban liveability across seven domains of employment, food, housing, public open space, social infrastructure, transport and walkability in Australia [10]. Algorithms measuring weighted street distance of individual dwellings to amenities and public transit have been developed to produce composite Walk Scores and Transit Scores in most US cities and some Canadian and Australian cities at the level of individual properties [11]. These are being linked with existing health cohorts to decipher associations with individual's active travel behaviours [12]. Furthermore, there are many large scale health studies being conducted around the world, including the UK Biobank study (described in the subsequent section), 45 and Up Study in New South Wales, Australia ${ }^{1}(N=250,000$ participants); EpiHealth Study, Sweden ${ }^{2}(N=300,000)$; China Kadoorie Biobank, China $^{3}(N=500,000)$; Million Death Study, India ${ }^{4}(N=1,000,000)$ and Hong Kong FAMILY Cohort $^{5}(N=46,000)$ to name just a few. These present us (BE and urban planners and designers, epidemiologists, health economists, public health researchers and policy makers) with a well-timed opportunity to join expertise and resources for an integrated and multidisciplinary global consortium to model and create national-level BE-health databases that can be turned into fine-tuned professional decision support and guidance systems. In the remaining part of this paper, we shall discuss some of the key issues and challenges in creation of healthy cities and ways to overcome them through interdisciplinary evidence generation on a large scale, planning and forecasting.

\footnotetext{
${ }_{1}^{1}$ https://www.saxinstitute.org.au/our-work/45-up-study/

${ }^{2} \mathrm{https} / /$ www.epihealth.se/For-scientists/

${ }^{3}$ http://www.ckbiobank.org/site/

${ }^{4} \mathrm{http} / / / \mathrm{www}$. cghr.org/projects/million-death-study-project/

${ }^{5}$ http://familycohort.sph.hku.hk/en/
} 


\section{In Pursuit of Better Evidence}

The late nineteenth century convergence of public health and urban planning was largely focused on reducing the risk of infectious diseases in cities. A century and a half later in advanced cities, the urgency has shifted to chronic disease, characterized by complex aetiology and long latency. Building healthy cities that reduce the burden of chronic diseases requires evidencebased interventions that design and retrofit BEs in a way that encourages healthy lifestyle and behaviour. To produce such evidence, we have to decipher the following:

- Generalizable associations between attributes of BE and specific behavioural and health outcomes (quantifiable in terms of strength and significance of such associations)

- Explicit associations that may exist across population clusters (with specific risk profiles), geographical context (cities, rural areas, specific countries like UK, USA, Australia and China) and transitions over time (with ageing and urban densification)

- Causal pathways from BE to specific health outcomes

- Reliability and robustness of the gathered evidence in guiding policy and identifying optimized paths from evidence to policy and practice

Health status and risk originates from complex interactions between an individual's inherent physiology and genetics interacting with contextual socio-economic, built and natural environmental variables. These interactions evolve over the life course $[6,7,13]$. Thus, an individual in an urban system may be conceptualized to be encapsulated by a 3D hypervolume called the health niche, essentially the epidemiological triad of person, place and time and comprising all health-influencing causal agents and processes functioning at the micro-, meso- and macro-level urban scales. The production and socio-spatial distribution of health is a result of spatiotemporal variations in an individual's health niche. As individuals come together to form a population, individual health niches self-organize, reconfiguring one another and intertwining together to constitute the coalesced niche for the population cluster (say a family, an ethnic community, etc). These coalesced niches have thus cumulative exposures of component individuals. Often, there are multiple multi-level environmental exposures active over varying durations and their effects are generally small but may nonetheless be significant to a specific health outcome. Figure 2a, b illustrates such a conceptual health niche model of chronic and infectious disease prevalence.

Because of the complex macro-micro level interactive processes over space-time coordinates, small scale studies with cross-sectional design fail to capture the aetiology and lack the power to influence policy [14]. Other bottlenecks to useful and accurate evidence gathering include a lack of standardized and objective measures of BE, the modifiable areal unit problem exacerbated by a reliance on census-defined spatial units of analysis and aggregate analysis due to lack of access to sensitive individual-level health datasets [15-17]. At present, a major proportion of BE-health studies are small in scale, cross-sectional in design and in most instances, not conclusive enough to support effective policies. Consequently, the pursuit of healthy cities continues to be haphazard, without an adequate scientific evidence base. But things are changing.

The new interest in urban planning among public health scientists over the past decade and the reciprocation of spatial analytical researchers from urban planning, geography and epidemiology is starting to disentangle the black box of contextual determinants of chronic disease. In the recent years, a series of epidemiological evidence on the relationships between the various attributes of $\mathrm{BE}$ with individual behaviour and health have emerged. These may be broadly classified as:

- BE as spaces promoting active living: This may be defined as the underlying capacity of the BE (its components, density and design) to provide a facilitative setting fostering active living via enhanced levels of physical activity in the form of walking, cycling and green exercise and thereby minimizing or offsetting the health costs of sedentary behaviours such as obesity and related chronic diseases as well as mental health disorders $[18,19]$. These studies originated from the formative research of Cervero and Kockelman [20] which isolated 3Ds; density, diversity and pedestrian-oriented designs as the three measures of the built environment having statistically significant influence upon walking and physical activity behaviour. Two more Ds - destination accessibility and distance to transit stops - were subsequently added to make it five Ds [21]. Lee and Moudon [22] further modified this to the $3 \mathrm{D}+\mathrm{R}$ concept to highlight destination, distance, density 


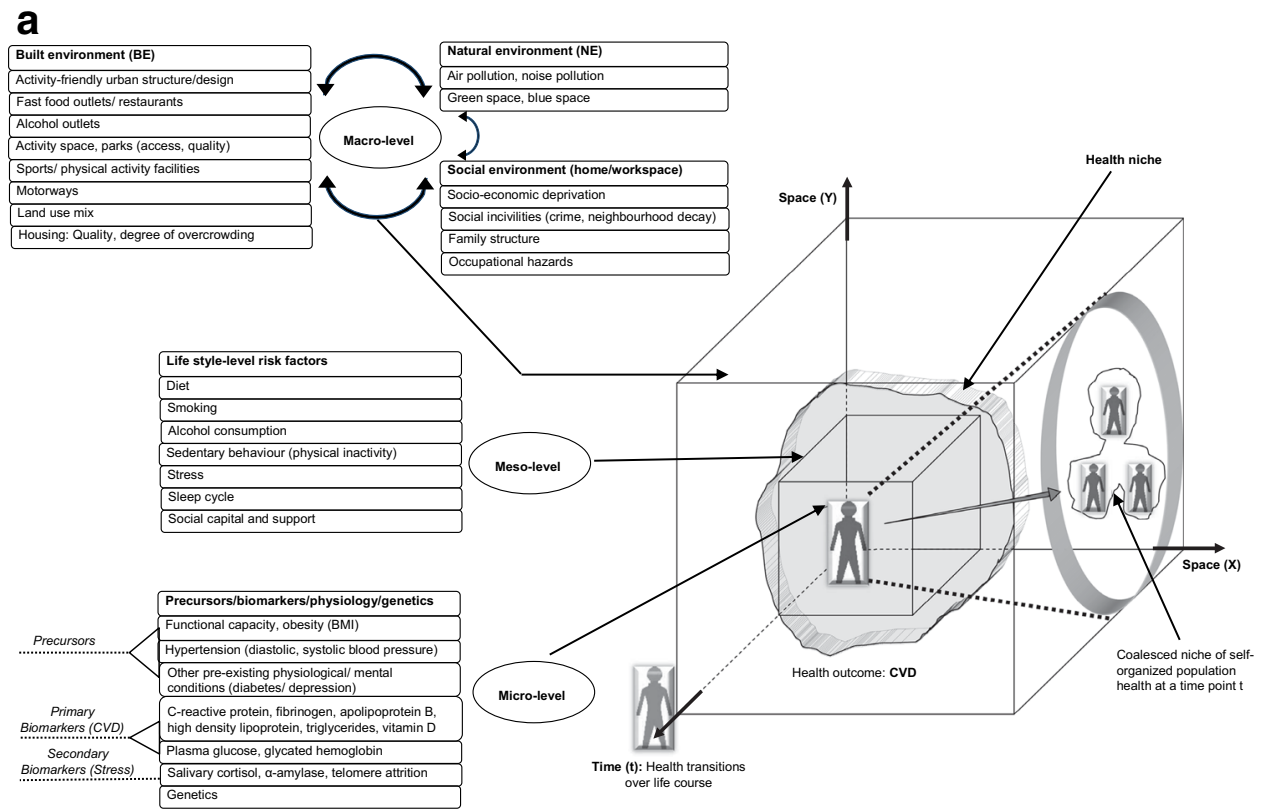

\section{b}
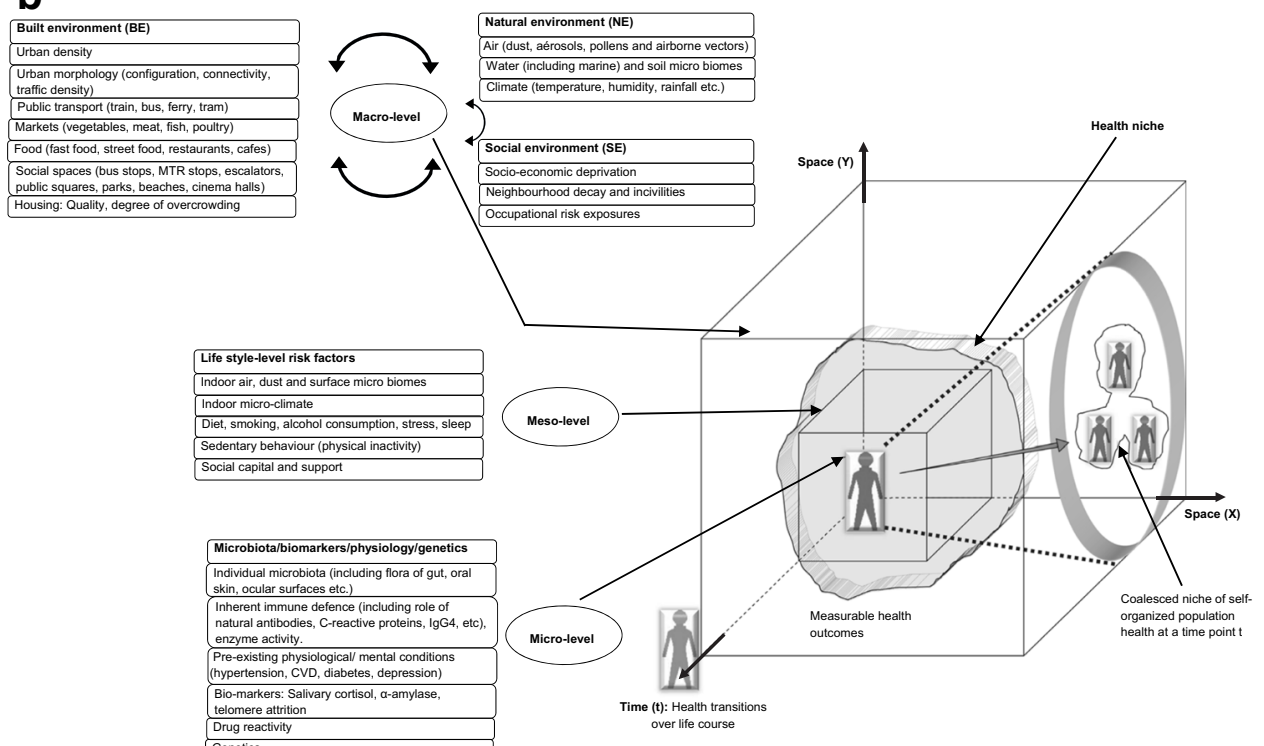

Fig. 2 Conceptual urban health niche model of multi-level risk clustering and risk pathways. a Gene, environment and the corresponding urban health niche for cardiovascular disease. b Gene, microbiome, built environment and the corresponding individual

and route as the built environment correlates of walking. Emerging from these seminal concepts relating $\mathrm{BE}$ and active travel, studies have examined specific attributes including density [23, 24], service health niche for microbial spread and infectious disease (adapted from the Health Niche model of Sarkar, Webster \& Gallacher, 2014) density [25, 26], land use mix [27] and street-level connectivity [28,29], as well as composite measures of sprawl [30, 31] and walkability [32]. Detailed research evidence has been reviewed elsewhere 
including the links between $\mathrm{BE}$ and physical activity [33-35], obesity [36], cardio-metabolic risks [37] and mental health [38].

The positive roles of urban green space in promoting physical and mental health have also been examined [39], including the role of street trees $[40,41]$, access to parks [42-44] and quality of green [45-47] as well as park characteristics and programmes [48, 49].

The significant importance of these multidimensional urban planning and design aspects in promoting active living have been highlighted in a recent Lancet Series in urban design, transport and health $[50,51]$.

Apart from the design aspects described above, another set of studies have examined the role of quality of residential environments (measured through street-level visual audits of contextual physical attributes such as physical incivilities, territorial functioning, defensible space, boardedup housing, perceptions of crime and safety etc.) primarily on mental health outcomes [52-56].

- BE as spaces promoting social interaction: Another set of studies have looked in to the role of BE as configured spaces promoting social interactions, fostering sense of community and sustaining specific levels of social capital [57-60]. The role of public green spaces in fostering social capital has also been studied [61, 62]. Evidence thus far points to positive effects on health [63] including active living via physical activity and reductions in obesity [64-66] and improved mental health [67-69].

- BE as spaces for therapeutic healing: Some studies have highlighted the beneficial role of natural spaces on health [70], especially their role in cities to act as spaces of natural healing and recovery from physiological and psychological stress [71-73].

- BE as spaces of socio-spatial inequality and deprivation: Several studies have looked in to the reciprocal interactions between place and underlying socialscape in shaping socio-spatial inequality and deprivation $[74,75]$ and how they influence multiple health outcomes [76-82].

- BE as spaces of stress and morbidity: Other studies have focused on health-inhibiting attributes of built environments as risk factors for stress and morbidity. These originate from the use of BE in ways that give rise to pollution of common-pool resources. The relationships between air pollution and multiple health outcomes have been established [83-87] and so have been the harmful effects of noise pollution [88-91] and heavy metal pollution [92] as well as high levels of arsenic [93, 94] and fluoride [95] in potable water. Another set of studies have examined the role of specific hazardous environments including waste disposal sites and landfills [96, 97] and powerlines [98, 99].

The relationship of built environment design with road traffic fatalities and injuries forms another active domain of investigation [100-102].

Other studies have examined the relationships between density of specific health-inhibiting destinations and health such as relationship between access to fast food outlets and adiposity [103-106] and alcohol outlets and related health harm [107-109].

- Indoor BE as spaces of stress and morbidity: These studies have investigated the role of indoor housinglevel BE factors on health [110] including physical conditions [111], indoor air quality [112-114], environmental tobacco smoke $[115,116]$ and residential radon [117].

The complex interactions between the abovementioned health-influencing factors prevalent in a city and the need for a system-based approach towards the creation of healthy cities have already been stressed by The Lancet Commission [3]. These research studies are yielding a more sophisticated evidence-base for shaping healthy cities. Particularly important developments in the new science of healthy cities include improvements in study design and objective BE measures.

Improvements in Study Design

Studies of the relationships between built environment and health are becoming stronger, meaning that they are able to conclude with greater statistical power, at finer levels of detail in terms of both health and built environment measures as well as gain deeper insights about causality in the reported associations. With the objective of capturing the complex aetiology inherent in chronic diseases, health researchers have recently begun to investigate individual-level health and disease outcomes as a function of genetics, anthropometrics, clinical measures, lifestyle, behaviour and socio-demographics, all measured over much larger scales than hitherto and with follow-up over regular periods of time. These are 
operationalized via national-level big prospective health cohorts. These mega population health studies constitute unprecedented and timely opportunities for exploring deeper and extending the science of health-focused town planning.

Health cohorts with large numbers of participants distributed across a wide socio-economic spectrum and geographical context not only ensures representativeness but it also means that there is substantial statistical power in detecting complex associations between the various attributes of $\mathrm{BE}$ and specific disease outcomes [118]. This is possible as a significantly large number of people having a specific health condition will be captured within a very large cohort. It also means that sufficient numbers of both diseased and healthy people are distributed across varying BE conditions (for example, living at different densities or within different landuse mixes) to be able to capture statistical significant associations where they exist. Longitudinal study design means that the health of cohort participants is followed up at regular temporal intervals, the goal is to be able to trace the graph of health and well-being over the life course and assess causal pathways from BE to health [119]. Where changes in BE can also be captured in the longitudinal database, the power of the study and the strength of the evidence is even greater.

\section{Objective BE Measures}

Deciphering the linkages and causal pathways from BE to specific health outcomes entails modelling and measuring health-relevant attributes of BE. In other words, $\mathrm{BE}$ characteristics within a functional neighbourhood of the dwelling location of an individual for whom we have medical data have to be measured and linked to his/her health data. In recent years, the focus has shifted towards the creation of objective GIS-based spatial measures of BE rather than self-reported perceptions of BE (associated with individual's subjectivity). This has been made possible through enhanced access to large national spatial databases (such as UK Ordnance Survey Mastermap, Swedish Lantmateriet and Digital topographic layers of Hong Kong Land Department), developments in Geographical Information System Science, corresponding advances in spatial modelling techniques, innovations in record linking and anonymization and advances in computational power. These have all helped open up the means for big data spatial modelling towards creation of standardized measures of $\mathrm{BE}$ that can be automated across very large areas, with manageable geo-computation and processing. It is now feasible to construct multi-level objective measures of $\mathrm{BE}$ and to replicate such processes, so that standardized sets of health-specific BE metrics can be linked to health cohorts across the world and fundamental BE-health hypotheses tested across different urban conditions.

In conducting individual-level BE-health studies, anonymising technology is as important as the data measures themselves. Recent developments in data linkage mean that sensitive health data can now be anonymized at household address and individual levels [120]. This has significant implications for healthy cities research as individual-level data (as illustrated by our urban niche model) can now be shared for multidisciplinary research and at the same time comply with rigorous privacy and access protocols that govern most health cohorts.

In BE-health studies, both BE and health data are typically cross-sectional. Treating health as longitudinal and $\mathrm{BE}$ as static is an improvement, justified on the grounds that the BE changes slowly and can be treated as fixed once it has been built. However, cause-effect modelling is enhanced when both health and BE are treated as dynamic. Just as we need longitudinal health data, it would be ideal to have a corresponding $\mathrm{BE}$ dataset over the period for which we have health data. This is possible in principle as most national-level spatial databases are regularly updated. Longitudinal BEhealth studies ensure temporal dynamism and robustness as one can model the changes in behaviour and health over a period of time in response to corresponding changes in environmental risks.

\section{UK Biobank Urban Morphometric Platform}

Here, we describe what we believe is one of the first examples illustrating the potential of large scale individual-level built environment-health data platform created to further the new science of healthy cities. It is a database capable over time of providing the evidence for interventions that will shape healthy twenty-first century cities, just as studies such as John Snow's provided evidence for healthy twentieth century cities. The UK Biobank Urban Morphometric Platform (UKBUMP) is a high resolution spatial database of individual-level health-specific BE metrics developed for half a million participants of the UK Biobank prospective cohort across 22 cities of England, Scotland and Wales [121]. 
The UK Biobank (UKB) is a national-level flagship epidemiological cohort of 500,000 participants aged 40-69 years and registered with the National Health Service. UKB participants provided extensive data on socio-demographics, lifestyle (including diet and physical activity), medical history, anthropometrics, cognitive function and biological samples (blood, urine and saliva) during the baseline phase of 2006-2010 [122, 123]. In addition, the world's biggest scanning project is currently underway wherein the brain, heart, bones, carotid arteries and abdominal fat are being scanned for 100,000 current participants of the UKB. Other key features include objective measures of individual physical activity captured by accelerometers for 100,000 participants, computerized visual acuity testing for 117,649 participants as well as the ongoing genotyping and measurement of a range of biochemical markers from biological samples collected all the participants of baseline. Record linkage with hospital inpatient data and primary care is currently underway. At present, follow-up data collection has taken place in the 20,000 participants of northwest England allowing early panel studies. In the future, follow-up will be rolled out to other centres, making UKBUMP into the prominent BE-health longitudinal study.

The UK Biobank study sought consent from individual participants. The UK Biobank Ethics and Governance Framework has strict measures to protect the confidentiality of the participants. All data and samples were (reversibly) anonymized, linked and stored to very high standards of security. All participant-identifying information have been encrypted for security and held as a stand-alone restricted access database controlled by senior UK Biobank staff member, while participants' data and samples are linked with the help of a generated unique linkage code. Data security measures include staff training and confidentiality pledges, physical and electronic controls on access to data, cybersecurity and physical security. The study has received ethical approvals from the North West Multi-centre Research Ethics Committee (MREC), the Community Health Index Advisory Group (CHIAG), the Patient Information Advisory Group (PIAG) and National Health Service National Research Ethics Service. Details are available at http://www.ukbiobank.ac.uk/principles-of-access/.

The BE data in UKBUMP comes from advanced spatial and network analyses of multiple UK-wide spatial databases, including UK Ordnance Survey Mastermap, AddressBase Premium, UKMap, UK Land
Registry, BlueSky colour infrared images and digital terrain models, and National Public Transport Access Node [121]. These are processed to model more than 750 objectively measured health-specific urban morphological metrics (morphometrics) characterizing the $\mathrm{BE}$ within functional neighbourhoods around UKB participants' geocoded dwelling locations. They were modelled at multiple spatial scales to capture the impacts of multi-level urban hierarchies upon individual behaviour and health (as hypothsized in the urban health niche model). These include metrics of residential density, age, type, health-specific land use densities of around 200 land use categories, street network proximity to more than 30 health-specific destinations, densities and street network distance to 19 different typologies of food-related destinations (for Greater London centres), high resolution measures of green exposures captured by remotely sensed colour infrared data (a 0.5 $\mathrm{m}$ resolution Normalized Difference Vegetation Index), degree terrain variability and neighbourhood-level deprivation. Key feature included urban configurational measures of physical accessibility captured at micro(400-1200 m), meso- (1500-5000 m) and macrolevels (7500-50,000 m).

UKBUMP is linked to the centralized UKB health records managed from UKB's home (http://www. ukbiobank.ac.uk/), creating a national platform for researching current challenges in healthy cities. UKBUMP introduces a step-change in the methodological rigour of BE-health research by making possible large-scale prospective multi-sectoral studies. Because of the size and spatial variation, it is also well adapted for large number natural experiments. Most questions that might reasonably be posed about BE-health associations can be addressed by UKBUMP. Figure 3 illustrates the potential of UKBUMP to act as a platform for multiple BE-health research. Because the size, objectivity and sophisticated multi-scalar nature of the BE metrics, UKBUMP also offers a chance to revisit with greater accuracy nearly all of the BE-health associations so far tested in published studies. Big data with considerable variability in the population characteristics and environmental exposures over space and time opens up new challenges and opportunities towards exploring more robust, sophisticated multi-layered modelling strategies that aim towards causal inference. Large scale UKBUMP association studies are being conducted to decipher generalizable evidence; interaction models developed on subsets of population with specific 


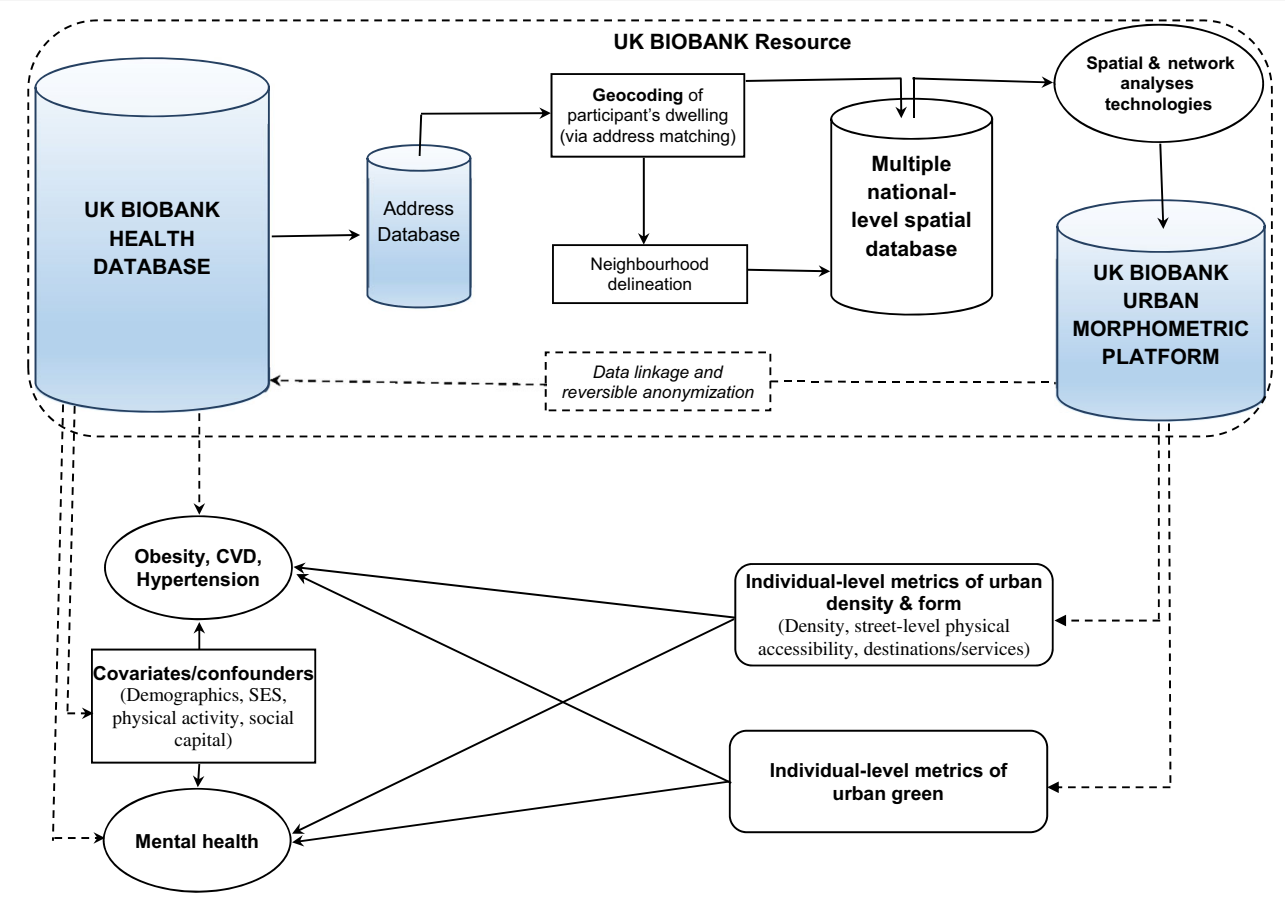

Fig. 3 UKBUMP as a platform for BE-health research (adapted from of Sarkar, Webster \& Gallacher, 2015)

characteristics (SES, environmental exposures) examine effect modification, while longitudinal multi-level, growth and structural equation models study causality in associations. Bayesian network models of public health can add built environment context to explore the discriminating power of urban morphometrics in diagnosis as well as prognosis. Follow-up response rate is another challenge in large longitudinal cohort studies, especially ensuring high follow-up rates to minimize loss of participants in subsequent phases. Presently, UKBUMP is a baseline built environment database; the challenge will be to model and measure the built environment at periodic intervals corresponding to the subsequent waves of examination. The latter two will ensure robust modelling of the sustained effects of built environment on behaviour and health.

\section{The Future: Factoring-In Health in Built Environment Resource Allocation}

The urban health challenge today is to find a way of actively involving the general public, policy makers, epidemiologists, public health professionals, urban planners, transport planners and designers in co-creating healthy cities. As ever, in complex resource governance, this will require demand and supply-side action at multiple spatial scales and across multiple sectors.

The language of incentives and economics (be it the economics of fat in our diet, pollution on our roads, health costs of free parking) is crucial for adjusting demand-side behaviour and in doing so, making radical shifts in infrastructure and service supply easier. This points to the need for factoring-in a wider set of positive/negative externalities of healthy/unhealthy behaviours as we allocate expenditure for city planning and public health budgets. Health externalities of urban living will be reduced if they can be internalized into someone's decision-making and economic calculus, just as road pricing can pass congestion externalities on to drivers and elicit reduced consumption of road space.

In the future, big data, individual-level analysis of social and private costs and benefits, smart sensing technology and increasing resource scarcity will all conspire to internalize more and more externalities via various kinds of pricing mechanism. Trunk road, bridge and city centre road pricing is just the start. Neighbourhood road pricing is being experimented with price congestion [124, 125]. Neighbourhood-level on-street parking pricing is being tested to balance the positive externalities of carborn trade with the negative externalities created by free parking [126]. The aesthetic, social and services values of 
our neighbourhoods have long been factored into private property prices [127, 128]. Recently, many have argued the case for pricing negative lifestyles $[129,130]$. The new genre of privately governed neighbourhoods makes the pricing of urban externalities more efficient. The majority of new homes in the USA are now governed by private neighbourhood governments and all but a tiny fraction of China's new homes are similarly in privately governed and managed, gated estates where local services are paid for via a monthly fee.

We pose the question 'how might health externalities be internalized as awareness of costs and benefits become better and more understood and better quantified'?

Public health campaigns use prices as a disincentive on alcohol and cigarettes. They also appeal directly to values and behaviour via advertising that exposes health risks in a way that is designed to shock. Public health goals are also, in the extreme, pursued via regulation, censorship and criminalization (class A drugs and free choice about which side of the road you drive on are both outlawed).

Planning is happily returning to a focus on social and health costs and benefits, which gives the profession greater precision and purpose than it has sometimes had during the previous century. Low-carbon cities, zero-carbon buildings, eco-cities, green cities, public transport cities, car-free cities, compact cities and healthy cities are all single issue planning doctrines focused on reducing particular externalities of agglomeration. The science underlying the doctrines is not generally well understood by planning and other built environment professionals, but it is increasing rapidly as big data and pressing urban problems draw a much wider mix of disciplinary expertise to study the urban question.

We agree with those suggesting that that we are on the cusp of a new urban science [131-135]. Twentieth century urban analytics were largely built on the back of aggregate data collected at sparse intervals by public bodies. They tended to be guided by inadequately specified theory (economic geography) and non-behavioural analogies with physical processes (social physics) and resulted in disconnect between behavioural psychology, behavioural economics and place making, or over-specified adaptations of mathematical economics relying on highly sophisticated models of the representative individual (geographical economics, urban economics and regional science). Urban health geography grew under such conditions, spurred on by the GIS revolution from the 1980s onward, but it was still also limited by aggregation, research protocols limiting generation of geocoded health dataset and their linkage, geo-computation processing power and other data limitations. Big data holds all such approaches to account. In health studies, data linkage and anonymization technology, massive computing power, cloud computing, remote smartphone-enabled technologies for auditing behaviour and environment, network analytics, AI-driven data-mining techniques, sophistications in spatial and temporal statistics come together to create a qualitatively and quantitatively new environment for modelling urban health holistically. Figure 2 gives our version of this environment. John Snow was limited to a 2D map representation of points in establishing healthy city analytics for the late nineteenth and early twentieth centuries. By the second half of the twentieth century, health geographers were publishing sophisticated choropleth maps with increasingly sophisticated statistical analytics that plotted error surfaces, weighted regression coefficients to adjust for spatial autocorrelation and so on. At the start of the twenty-first century, we are back to points, only this time we have many more of them and multiple attributes for each. This lays the foundation for a new chapter in the science of healthy cities and evidencebased town planning and urban design.

How might we move from big data urban health platforms such as UKBUMP to incentives that price-in health costs in a way that might more readily affect behaviour? As starting point, nationwide neighbourhood-level odds/ prevalence of most disease outcomes can now be modelled after adjustments for major environmental and individual-level confounders. This would give the specific odds of each disease as well as the significant built environmental predictors for each small area local authorities. This is the next step and takes us from knowledge calibrated at the individual-level back to small-area policy and governance, but this time, based on precise models that generate outputs taking individuals as the fundamental unit of analyses. This is our next plan for UKBUMP and grant proposals are currently under discussion. Specifically, we intend to:

- Calculate the odds of specific behaviours (e.g. physical activity, diet) and disease outcomes (e.g. obesity, CVD, depression) for an individual residing in a particular dwelling and exposed to a specific BE with a specific set of environmental risks. We look upon this as a national grid of urban health risk

- Use the national health risk grid to inform policy, influencing the way our cities are designed and retrofitted 
- Develop predictive Bayesian models for specific future scenarios. This will entail creation of various scenarios of urban growth and development and corresponding modelling of odds of specific behaviour and disease, thereby forecasting spatiotemporal variations in the national health risk grid corresponding to specific scenarios

- Develop health economic models based on the BE risk profiles and calculate economic benefits associated with health-specific BE improvements

- Allocate budgets and resources to ameliorate negative externalities based on the above-mentioned models

Local governments would employ such a database to develop predictive scenarios of neighbourhood-level disease burdens for chronic disease and corresponding health expenditures modelled in response to changes in the city's BE. These would form the basis of neighbourhoodspecific investments towards preventive interventions. Those interventions might include the following:

- Targeted regimes of incentivization/disincentivization of positive/negative behaviour and lifestyles and that stimulate individual consumption behaviour change (for example, from sedentary to healthy living, more walking, healthier food, less driving) and $\mathrm{BE}$ production-behaviour change (more high quality local green space, more co-owned community gardens, healthy well-connected road layouts that encourage walking and discourage vehicles, better buffer between roads and housing)

- Environmental design interventions and retrofitting to correct identified problem areas in $\mathrm{BE}$; i.e. neighbourhood-specific BE attributes related to housing and neighbourhood design, road network design, land use density and mix, allocation, size, distribution and quality of urban green spaces as well as optimization of accessibility to health-specific services

- More targeted planning and building regulations to promote healthy buildings, neighbourhoods and whole cities

- Public health programme directed at the use of urban space

Focused neighbourhood-specific interventions based on evidence have the potential for saving billions of pounds of future health expenditures.

Furthermore, such a risk matrix will also entail calculation of risk scores (for example through propagation speed estimation in cases of infectious diseases) and scenario generation as well as targeted syndromic surveillance for potential episodes of toxic release and outbreaks of infectious disease in high density urban environments.

\section{Conclusion}

The starting point for designing, calibrating and managing more healthy cities is to understand more fully the associations and the underlying causality between urban configuration and health. After decades of modern city planning, we still do not know with any precision, for example, whether it is better for public health to allocate all of a city's green space in one large park or to allocate it in multiple small neighbourhood parks or something in between. Something in between is a sensible idea and leads to the commonly used idea of a green space hierarchy. But which kind of hierarchies gives better health results than others? How do you design a hierarchy of green spaces that takes into account the scientific finding that elderly peoples' health benefits more from having to walk a certain distance to a green space than from having green space on their doorstep? What is that 'certain distance' for different age groups? How might this shape the more healthy design of the many bespoke elderly neighbourhoods that will characterize cities of the future in the rapidly ageing societies of Europe, USA and China?

As another example, we know from existing studies that the geometric and topological configuration of a city's road grid influences both total walking behaviour and the spatial and temporal distribution of a given quantity of walking $[47,136]$. Real estate and urban economic studies have verified casual intuition that certain street and land-use configurations yield better localized pedestrian footfall and commercial rents. If that is so, then there is also likely to be systematic patterns of health associated with street configuration, and for that matter, health and property prices.

Throughout the history of civilization, technology has helped people adjust their habitats to experience and accumulate knowledge about relationships between habitat location and design and health. Societies quickly learned not to live in the shadows of active volcanoes, though amazingly, some still do. Village location evolved over time in response to locational factors - into the hills in times of insecurity, proximity to fresh water bodies in times of drought, nearer the sea in times of prosperity and trading and so on, up-river as an interior economy developed. Cities of the industrial era quickly organized themselves to 
separate people from industrial pollution, with those who could afford it bidding higher prices for land at a distance from and up-wind of factories. A seminal breakthrough came in London with the health mapping of John Snow, who discovered by simple point mapping, that the cholera outbreak in Soho was caused by a polluted public water standpipe. Since Snow, the science of spatial statistics, epidemiology, health geography and gene-environment interactions have moved on and so have the availability of data and computing power with it. For the first time in human history, we are now in a position to begin to trace the health associations of very fine variations in urban configuration. Within a few months of the time of writing of this paper, the UK will have an unsurpassed nationallevel data infrastructure and evidence-base for predictive modelling of the relationship between most conceivable urban planning and design configurations and specific health outcomes. With the UKBUMP in place, further small-scale statistical studies and case studies of health-BE associations will largely be redundant, unless they are designed to probe deeper into UKBUMP findings, especially in respect of causality. Urban planning researchers interested in contributing to the new urban science of healthy cities are encouraged to consider using UKBUMP for associational studies, time series studies and natural experiments into BEhealth relationships and to test and re-think planning and design doctrines inherited from another era.

Acknowledgements The work has been funded by the UK Economic and Social Research Council under its Transformative Research scheme (grant number ES/L003201/1); the UK Biobank seed grant; and HKUrbanLab, University of Hong Kong's University Development Fund.

Compliance with Ethical Standards The UK Biobank study described here has received ethical approvals from the North West Multi-centre Research Ethics Committee (MREC), the Community Health Index Advisory Group (CHIAG), the Patient Information Advisory Group (PIAG) and National Health Service National Research Ethics Service. Details are available at http://www. ukbiobank.ac.uk/principles-of-access/.

\section{References}

1. Webster CJ, Lai LW-C. Property rights, planning and markets: managing spontaneous cities. Cheltenham, UK: Edward Elgar Publishing; 2003.

2. Wu F, Webster CJ. Marginalization in urban China: comparative perspectives. Hampshire, UK: Palgrave Macmillan; 2010.
3. Rydin Y, Bleahu A, Davies M, et al. Shaping cities for health: complexity and the planning of urban environments in the 21st century. Lancet. 2012; 379(9831): 2079-2108.

4. Vlahov D, Galea S. Urbanization, urbanicity, and health. $J$ Urban Health. 2002; 79(4 SUPPL. 1): S1-S12.

5. The Marmot Review. Fair society healthy lives: the Marmot review. London, UK: The Marmot Review; 2010.

6. Sarkar C, Webster C, Gallacher J. Healthy cities: public health through urban planning. Cheltenham, UK: Edward Elgar Publishing; 2014.

7. McMichael AJ. Prisoners of the proximate: loosening the constraints on epidemiology in an age of change. Am J Epidemiol. 1999; 149(10): 887-897.

8. Brownson RC, Haire-Joshu D, Luke DA. Shaping the context of health: a review of environmental and policy approaches in the prevention of chronic diseases. Annu Rev Public Health. 2006; 27: 341-370.

9. Chokshi DA, Farley TA. The cost-effectiveness of environmental approaches to disease prevention. $N$ Engl J Med. 2012; 367(4): 295-297.

10. Badland H, Whitzman C, Lowe M, et al. Urban liveability: emerging lessons from Australia for exploring the potential for indicators to measure the social determinants of health. Soc Sci Med. 2014; 111: 64-73.

11. Walkscore. Walk score and transit score methodology. 2015. Available at: https://www.walkscore.com/methodology. shtml. Accessed: 10/05/2016.

12. Hirsch JA, Moore KA, Evenson KR, Rodriguez DA, Roux AVD. Walk Score ${ }^{\circledR}$ and Transit Score $\AA$ and walking in the multi-ethnic study of atherosclerosis. Am J Prev Med. 2013; 45(2): 158-166.

13. Macintyre S, Ellaway A, Cummins S. Place effects on health: how can we conceptualise, operationalise and measure them? Soc Sci Med. 2002; 55(1): 125-139.

14. Gallacher J. Commentary: type A behaviour and heart disease: no less inscrutable in Japan. Int J Epidemiol. 2008; 37(6): 1406-1407.

15. Pearce N. The ecological fallacy strikes back. J Epidemiol Community Health. 2000; 54(5): 326-327.

16. Diez Roux AV. Estimating neighborhood health effects: the challenges of causal inference in a complex world. Soc Sci Med. 2004; 58(10): 1953-1960.

17. Kwan M-P. From place-based to people-based exposure measures. Soc Sci Med. 2009; 69(9): 1311-1313.

18. Eyler AA, Brownson RC, Bacak SJ, Housemann RA. The epidemiology of walking for physical activity in the United States. Med Sci Sports Exerc. 2003; 35(9): 1529-1536.

19. Warburton DE, Nicol CW, Bredin SS. Health benefits of physical activity: the evidence. Can Med Assoc J. 2006; 174(6): 801-809.

20. Cervero R, Kockelman K. Travel demand and the 3Ds: density, diversity, and design. Transp Res Part D: Transp Environ. 1997; 2(3): 199-219.

21. Ewing R, Cervero R. Travel and the built environment: a synthesis. Transp Res Rec. 1780; 2001: 87-114.

22. Lee C, Moudon AV. The 3Ds+R: quantifying land use and urban form correlates of walking. Transp Res Part D: Transp Environ. 2006; 11(3): 204-215.

23. Forsyth A, Oakes JM, Schmitz KH, Hearst M. Does residential density increase walking and other physical activity? Urban Stud. 2007; 44(4): 679-697. 
24. Rundle A, Roux AVD, Freeman LM, Miller D, Neckerman KM, Weiss CC. The urban built environment and obesity in New York City: a multilevel analysis. Am J Health Promot. 2007; 21(4 suppl): 326-334.

25. Giles-Corti B, Macintyre S, Clarkson JP, Pikora T, Donovan RJ. Environmental and lifestyle factors associated with overweight and obesity in Perth, Australia. Am J Health Promot. 2003; 18(1): 93-102.

26. Gordon-Larsen P, Nelson MC, Page P, Popkin BM. Inequality in the built environment underlies key health disparities in physical activity and obesity. Pediatrics. 2006; 117(2): 417-424.

27. Mobley LR, Root ED, Finkelstein EA, Khavjou O, Farris RP, Will JC. Environment, obesity, and cardiovascular disease risk in low-income women. Am J Prev Med. 2006; 30(4): 327-332. e321.

28. Grafova IB, Freedman VA, Kumar R, Rogowski J. Neighborhoods and obesity in later life. Am J Public Health. 2008; 98(11): 2065-2071.

29. Sarkar C, Gallacher J, Webster C. Built environment configuration and change in body mass index: the caerphilly prospective study (CaPS). Health Place. 2013; 19: 33-44.

30. Ewing R, Schmid T, Killingsworth R, Zlot A, Raudenbush S. Relationship between urban sprawl and physical activity, obesity, and morbidity. Am J Health Promot. 2003; 18(1): $47-57$.

31. Lopez R. Urban sprawl and risk for being overweight or obese. Am J Public Health. 2004; 94(9): 1574-1579.

32. Frank LD, Sallis JF, Conway TL, Chapman JE, Saelens BE, Bachman W. Many pathways from land use to health: associations between neighborhood walkability and active transportation, body mass index, and air quality. J Am Plan Assoc. 2006; 72(1): 75-87.

33. Saelens BE, Handy SL. Built environment correlates of walking: a review. Med Sci Sports Exerc. 2008; $40(7$ Suppl): S550.

34. Brownson RC, Hoehner CM, Day K, Forsyth A, Sallis JF. Measuring the built environment for physical activity: state of the science. Am J Prev Med. 2009; 36(4): S99-S123. e112.

35. Wang Y, Chau C, Ng W, Leung T. A review on the effects of physical built environment attributes on enhancing walking and cycling activity levels within residential neighborhoods. Cities. 2016; 50: 1-15.

36. Papas MA, Alberg AJ, Ewing R, Helzlsouer KJ, Gary TL, Klassen AC. The built environment and obesity. Epidemiol Rev. 2007; 29(1): 129-143.

37. Leal C, Chaix B. The influence of geographic life environments on cardiometabolic risk factors: a systematic review, a methodological assessment and a research agenda. Obes Rev. 2011; 12(3): 217-230.

38. Evans GW. The built environment and mental health. $J$ Urban Health. 2003; 80(4): 536-555.

39. Lee ACK, Maheswaran R. The health benefits of urban green spaces: a review of the evidence. J Public Health. 2011; 33(2): 212-222.

40. Lovasi GS, Quinn JW, Neckerman KM, Perzanowski MS, Rundle A. Children living in areas with more street trees have lower prevalence of asthma. J Epidemiol Community Health. 2008; 62(7): 647-649.
41. Lovasi GS, Jacobson JS, Quinn JW, Neckerman KM, Ashby-Thompson MN, Rundle A. Is the environment near home and school associated with physical activity and adiposity of urban preschool children? J Urban Health. 2011; 88(6): 1143-1157.

42. Takano T, Nakamura K, Watanabe M. Urban residential environments and senior citizens' longevity in megacity areas: the importance of walkable green spaces. $J$ Epidemiol Community Health. 2002; 56(12): 913-918.

43. De Vries S, Verheij RA, Groenewegen PP, Spreeuwenberg P. Natural environments-healthy environments? An exploratory analysis of the relationship between greenspace and health. Environ Plan A. 2003; 35(10): 1717-1732.

44. Sugiyama T, Leslie E, Giles-Corti B, Owen N. Associations of neighbourhood greenness with physical and mental health: do walking, social coherence and local social interaction explain the relationships? J Epidemiol Community Health. 2008; 62(5): e9.

45. Pereira G, Foster S, Martin K, et al. The association between neighborhood greenness and cardiovascular disease: an observational study. BMC Public Health. 2012; 12(1): 466.

46. Pereira G, Christian H, Foster S, et al. The association between neighborhood greenness and weight status: an observational study in Perth Western Australia. Environ Health. 2013; 12: 49.

47. Sarkar C, Webster C, Pryor M, et al. Exploring associations between urban green, street design and walking: results from the Greater London boroughs. Landsc Urban Plan. 2015; 143: 112-125.

48. McCormack GR, Rock M, Toohey AM, Hignell D. Characteristics of urban parks associated with park use and physical activity: a review of qualitative research. Health Place. 2010; 16(4): 712-726.

49. Wolch J, Jerrett M, Reynolds K, et al. Childhood obesity and proximity to urban parks and recreational resources: a longitudinal cohort study. Health Place. 2011; 17(1): 207214.

50. Giles-Corti B, Vernez-Moudon A, Reis R, et al. City planning and population health: a global challenge. Lancet. 2016. doi:10.1016/S0140-6736(16)30066-6.

51. Sallis JF, Bull F, Burdett R, et al. Use of science to guide city planning policy and practice: how to achieve healthy and sustainable future cities. Lancet. 2016. doi:10.1016 /S0140-6736(16)30068-X.

52. Weich S, Blanchard M, Prince M, Burton E, Erens B, Sproston K. Mental health and the built environment: cross-sectional survey of individual and contextual risk factors for depression. $\mathrm{Br} J$ Psychiatry. 2002; 180(5): 428-433.

53. Cohen DA, Mason C, Bedimo A, Scribner R, Basolo V, Farley TA. Neighborhood physical conditions and health. Am J Public Health. 2003; 93(3): 467-471.

54. Galea S, Ahern J, Rudenstine S, Wallace Z, Vlahov D. Urban built environment and depression: a multilevel analysis. J Epidemiol Community Health. 2005; 59(10): 822827.

55. Thomas H, Weaver N, Patterson J, et al. Mental health and quality of residential environment. Br J Psychiatry. 2007; 191(6): 500-505. 
56. Araya R, Montgomery A, Rojas G, et al. Common mental disorders and the built environment in Santiago, Chile. Br J Psychiatry. 2007; 190: 394-401.

57. Talen E. Sense of community and neighbourhood form: an assessment of the social doctrine of new urbanism. Urban Stud. 1999; 36(8): 1361-1379.

58. Lund H. Pedestrian environments and sense of community. J Plan Educ Res. 2002; 21(3): 301-312.

59. Leyden KM. Social capital and the built environment: the importance of walkable neighborhoods. Am J Public Health. 2003; 93(9): 1546-1551.

60. Cohen DA, Inagami S, Finch B. The built environment and collective efficacy. Health Place. 2008; 14(2): 198-208.

61. Kweon B-S, Sullivan WC, Wiley AR. Green common spaces and the social integration of inner-city older adults. Environ Behav. 1998; 30(6): 832-858.

62. Sullivan WC, Kuo FE, Depooter SF. The fruit of urban nature vital neighborhood spaces. Environ Behav. 2004; 36(5): 678-700.

63. Kawachi I, Berkman L. Social cohesion, social capital, and health. In: Kawachi I, Berkman L, eds. Social epidemiology. New York, NY: Oxford University Press; 2000: 174 190.

64. Kim D, Subramanian S, Gortmaker SL, Kawachi I. US state-and county-level social capital in relation to obesity and physical inactivity: a multilevel, multivariable analysis. Soc Sci Med. 2006; 63(4): 1045-1059.

65. Poortinga W. Perceptions of the environment, physical activity, and obesity. Soc Sci Med. 2006; 63(11): 28352846.

66. Cohen DA, Finch BK, Bower A, Sastry N. Collective efficacy and obesity: the potential influence of social factors on health. Soc Sci Med. 2006; 62(3): 769-778.

67. Kawachi I, Berkman LF. Social ties and mental health. $J$ Urban Health. 2001; 78(3): 458-467.

68. McKenzie K, Whitley R, Weich S. Social capital and mental health. Br J Psychiatry. 2002; 181(4): 280-283.

69. Almedom AM. Social capital and mental health: an interdisciplinary review of primary evidence. Soc Sci Med. 2005; 61(5): 943-964.

70. Hartig T, Mitchell R, De Vries S, Frumkin H. Nature and health. Annu Rev Public Health. 2014; 35: 207-228.

71. Grahn P, Stigsdotter UA. Landscape planning and stress. Urban For Urban Green. 2003; 2(1): 1-18.

72. Hartig T, Evans GW, Jamner LD, Davis DS, Gärling T. Tracking restoration in natural and urban field settings. $J$ Environ Psychol. 2003; 23(2): 109-123.

73. Woo J, Tang N, Suen E, Leung J, Wong M. Green space, psychological restoration, and telomere length. Lancet. 2009; 373(9660): 299-300.

74. Bernard P, Charafeddine R, Frohlich KL, Daniel M, Kestens Y, Potvin L. Health inequalities and place: a theoretical conception of neighbourhood. Soc Sci Med. 2007; 65(9): 1839-1852.

75. Cummins S, Curtis S, Diez-Roux AV, Macintyre S. Understanding and representing 'place' in health research: a relational approach. Soc Sci Med. 2007; 65(9): 18251838.

76. Caspi A, Taylor A, Moffitt TE, Plomin R. Neighborhood deprivation affects children's mental health: environmental risks identified in a genetic design. Psychol Sci. 2000; 11(4): 338-342.

77. Macintyre S. Deprivation amplification revisited; or, is it always true that poorer places have poorer access to resources for healthy diets and physical activity? Int J Behav Nutr Phys Act. 2007; 4(1): 1.

78. Lovasi GS, Hutson MA, Guerra M, Neckerman KM. Built environments and obesity in disadvantaged populations. Epidemiol Rev. 2009. doi:10.1093/epirev/mxp005.

79. Mitchell R, Popham F. Effect of exposure to natural environment on health inequalities: an observational population study. Lancet. 2008; 372(9650): 1655-1660.

80. Ward Thompson C, Roe J, Aspinall P, Mitchell R, Clow A, Miller D. More green space is linked to less stress in deprived communities: evidence from salivary cortisol patterns. Landsc Urban Plan. 2012; 105(3): 221-229.

81. Weich S, Lewis G. Material standard of living, social class, and the prevalence of the common mental disorders in Great Britain. J Epidemiol Community Health. 1998; 52(1): 8-14.

82. Sallis JF, Saelens BE, Frank LD, et al. Neighborhood built environment and income: examining multiple health outcomes. Soc Sci Med. 2009; 68(7): 1285-1293.

83. Pope CA III, Burnett RT, Thun MJ, et al. Lung cancer, cardiopulmonary mortality, and long-term exposure to fine particulate air pollution. J Am Med Assoc. 2002; 287(9): 1132-1141.

84. Vineis P, Husgafvel-Pursiainen K. Air pollution and cancer: biomarker studies in human populations. Carcinogenesis. 2005; 26(11): 1846-1855.

85. Pope CA III, Dockery DW. Health effects of fine particulate air pollution: lines that connect. J Air Waste Manage Assoc. 2006; 56(6): 709-742.

86. Kampa M, Castanas E. Human health effects of air pollution. Environ Pollut. 2008; 151(2): 362-367.

87. Hoek G, Krishnan RM, Beelen R, et al. Long-term air pollution exposure and cardio-respiratory mortality: a review. Environ Health. 2013; 12(1): 1.

88. Stansfeld SA, Matheson MP. Noise pollution: non-auditory effects on health. Br Med Bull. 2003; 68(1): 243-257.

89. Stansfeld SA, Berglund B, Clark C, et al. Aircraft and road traffic noise and children's cognition and health: a crossnational study. Lancet. 2005; 365(9475): 1942-1949.

90. Babisch W. Road traffic noise and cardiovascular risk. Noise Health. 2008; 10(38): 27.

91. Zaharna M, Guilleminault C. Sleep, noise and health: review. Noise Health. 2010; 12(47): 64.

92. Järup L. Hazards of heavy metal contamination. $\mathrm{Br} \mathrm{Med}$ Bull. 2003; 68(1): 167-182.

93. Yoshida T, Yamauchi H, Sun GF. Chronic health effects in people exposed to arsenic via the drinking water: doseresponse relationships in review. Toxicol Appl Pharmacol. 2004; 198(3): 243-252.

94. Navas-Acien A, Sharrett AR, Silbergeld EK, et al. Arsenic exposure and cardiovascular disease: a systematic review of the epidemiologic evidence. Am J Epidemiol. 2005; 162(11): 1037-1049.

95. Ayoob S, Gupta AK. Fluoride in drinking water: a review on the status and stress effects. Crit Rev Environ Sci Technol. 2006; 36(6): 433-487. 
96. Porta D, Milani S, Lazzarino AI, Perucci CA, Forastiere F. Systematic review of epidemiological studies on health effects associated with management of solid waste. Environ Health. 2009; 8(1): 1.

97. Elliott P, Richardson S, Abellan JJ, et al. Geographic density of landfill sites and risk of congenital anomalies in England. Occup Environ Med. 2009; 66(2): 81-89.

98. Feychting M, Ahlbom A, Kheifets L. EMF and health. Annu Rev Public Health. 2005; 26: 165-189.

99. Draper G, Vincent T, Kroll ME, Swanson J. Childhood cancer in relation to distance from high voltage power lines in England and Wales: a case-control study. $\mathrm{Br} \mathrm{Med} J$. 2005; 330(7503): 1290.

100. Ewing R, Dumbaugh E. The built environment and traffic safety a review of empirical evidence. J Plan Lit. 2009; 23(4): 347-367.

101. Dumbaugh E, Rae R. Safe urban form: revisiting the relationship between community design and traffic safety. $J \mathrm{Am}$ Plan Assoc. 2009; 75(3): 309-329.

102. Grundy C, Steinbach R, Edwards P, Green J, Armstrong B, Wilkinson P. Effect of $20 \mathrm{mph}$ traffic speed zones on road injuries in London, 1986-2006: controlled interrupted time series analysis. $\mathrm{Br}$ Med J. 2009; 339: b4469.

103. White M. Food access and obesity. Obes Rev. 2007; 8(s1): 99-107.

104. Cummins S, Macintyre S. Food environments and obesity-neighbourhood or nation? Int J Epidemiol. 2006; 35(1): 100-104.

105. Caspi CE, Sorensen G, Subramanian S, Kawachi I. The local food environment and diet: a systematic review. Health Place. 2012; 18(5): 1172-1187.

106. Cobb LK, Appel LJ, Franco M, Jones-Smith JC, Nur A, Anderson CA. The relationship of the local food environment with obesity: a systematic review of methods, study quality, and results. Obesity. 2015; 23(7): 1331-1344.

107. Popova S, Giesbrecht N, Bekmuradov D, Patra J. Hours and days of sale and density of alcohol outlets: impacts on alcohol consumption and damage: a systematic review. Alcohol Alcohol. 2009; 44(5): 500-516.

108. Campbell CA, Hahn RA, Elder R, et al. The effectiveness of limiting alcohol outlet density as a means of reducing excessive alcohol consumption and alcohol-related harms. Am J Prev Med. 2009; 37(6): 556-569.

109. Connor JL, Kypri K, Bell ML, Cousins K. Alcohol outlet density, levels of drinking and alcohol-related harm in New Zealand: a national study. J Epidemiol Commun Health. 2011; 65(10): 841-846.

110. Krieger J, Higgins DL. Housing and health: time again for public health action. Am J Public Health. 2002; 92(5): 758768.

111. Howden-Chapman P. Housing standards: a glossary of housing and health. J Epidemiol Community Health. 2004; 58(3): 162-168.

112. Jones AP. Indoor air quality and health. Atmos Environ. 1999; 33(28): 4535-4564.

113. Zhang JJ, Smith KR. Indoor air pollution: a global health concern. Br Med Bull. 2003; 68(1): 209-225.

114. Dales R, Liu L, Wheeler AJ, Gilbert NL. Quality of indoor residential air and health. Can Med Assoc J. 2008; 179(2): 147-152.
115. Thun M, Henley J, Apicella L. Epidemiologic studies of fatal and nonfatal cardiovascular disease and ETS exposure from spousal smoking. Environ Health Perspect. 1999; 107(SUPPL. 6): 841-846.

116. U.S. Department of Health and Human Services. the health consequences of involuntary exposure to tobacco smoke: a report of the surgeon general. Atlanta, GA: U.S. Department of Health and Human Services, Centers for Disease Control and Prevention, Coordinating Center for Health Promotion, National Center for Chronic Disease Prevention and Health Promotion, Office on Smoking and Health; 2006.

117. Darby S, Hill D, Auvinen A, et al. Radon in homes and risk of lung cancer: collaborative analysis of individual data from 13 European case-control studies. Br Med J. 2005; 330(7485): 223.

118. Manolio TA, Weis BK, Cowie CC, et al. New models for large prospective studies: is there a better way? Am J Epidemiol. 2012; 175(9): 859-866.

119. Ben-Shlomo Y, Kuh D. A life course approach to chronic disease epidemiology: conceptual models, empirical challenges and interdisciplinary perspectives. Int J Epidemiol. 2002; 31(2): 285-293.

120. Lyons RA, Ford DV, Moore L, Rodgers SE. Use of data linkage to measure the population health effect of nonhealth-care interventions. Lancet. 2014; 383(9927): 15171519.

121. Sarkar C, Webster C, Gallacher J. UK Biobank Urban Morphometric Platform (UKBUMP) - a nationwide resource for evidence-based healthy city planning and public health interventions. Ann GIS. 2015; 21(2): 135-148.

122. UK Biobank. UK Biobank: Protocol for a large-scale prospective epidemiological resource. UK Biobank. Available at: http://www.ukbiobank.ac.uk/wp-content/uploads/2011 /11/UK-Biobank-Protocol.pdf;2007. Accessed 15 April 2016.

123. Allen N, Sudlow C, Downey P, et al. UK Biobank: current status and what it means for epidemiology. Health Policy Technol. 2012; 1(3): 123-126.

124. de Palma A, Lindsey R. Traffic congestion pricing methodologies and technologies. Transp Res C. 2011; 19(6): 1377-1399.

125. Arnott R, De Palma A, Lindsey R. Economics of a bottleneck. J Urban Econ. 1990; 27(1): 111-130.

126. Shoup DC. The high cost of free parking. Chicago, IL: Planners Press; 2005.

127. Morancho AB. A hedonic valuation of urban green areas. Landsc Urban Plan. 2003; 66(1): 35-41.

128. Mahan BL, Polasky S, Adams RM. Valuing urban wetlands: a property price approach. Land Econ. 2000; 76(1): 100-113.

129. Leicester A, Windmeijer F. The 'fat tax': economic incentives to reduce obesity. IFS Briefing Notes BN49. London, UK: Institute for Fiscal Studies; 2004. Available at: http://discovery.ucl.ac.uk/14931/. Accessed: 24/04/2016.

130. Mytton O, Gray A, Rayner M, Rutter H. Could targeted food taxes improve health? J Epidemiol Community Health. 2007; 61(8): 689-694.

131. Batty M. Smart cities, big data. Environ Plan Part B. 2012; 39(2): 191. 
132. Batty M, Axhausen KW, Giannotti F, et al. Smart cities of the future. Eur Phys J Spec Top. 2012; 214(1): 481-518.

133. Batty M. Big data, smart cities and city planning. Dialogues Hum Geogr. 2013; 3(3): 274-279.

134. Williams S. More than data: working with big data for civics. ISJLP. 2015; 11: 181.
135. Kitchin R. Big data and human geography opportunities, challenges and risks. Dialogues Hum Geogr. 2013; 3(3): 262-267.

136. Hillier B, Penn A, Hanson J, Grajewski T, Xu J. Natural movement: or, configuration and attraction in urban pedestrian movement. Environ Plann B Plann Des. 1993; 20(1): 29-66. 